\title{
EFFECTS OF VARIOUS PSYCHOTOMIMETIC AGENTS ON THE EEG AND ACETYLCHOLINE RELEASE FROM THE CEREBRAL CORTEX OF BRAINSTEM TRANSECTED CATS*
}

\author{
E. F. Domino and A. BARTOLINI $\dagger$ \\ Neuropsychopharmacology Research Program, Department of Pharmacology, \\ University of Michigan, Ann Arbor, Michigan 48104
}

(Accepted 2 February 1972)

\begin{abstract}
Summary-The effects of i.v. administration of $\Delta^{*}$ THC, phencyclidine, the pyrrolidyl and piperidyl isomers of Ditran, and LSD-25 were determined on the spontaneous neocortical EEG and release of acetylcholine (ACh) from the somatosensory cortex of brainstem transected cats. $\Delta^{\theta} \mathrm{THC}$ was given in doses of $0.5-11 \mathrm{mg} / \mathrm{kg}$ i.v. to animals with a pretrigeminal midpontine transection. $\Delta^{\theta}$ THC produced neocortical high voltage EEG slow waves which were more prominent in the frontal areas of the brain. At the same time, arterial blood pressure and heart rate were reduced slightly. These effects were observable in doses of $0.5 \mathrm{mg} / \mathrm{kg}$, but were more obvious at larger doses. The administration of amphetaminc promptly antagonized the EEG changes induced by $\Delta^{9} \mathrm{THC}$. In doses of $0.5 \mathrm{mg} / \mathrm{kg}, \Delta^{9} \mathrm{THC}$ caused either no effect or a slight increase in the release of $\mathrm{ACh}$ from the cortex. Larger doses caused a progressive decrease in ACh release. The effects of $\Delta^{9} \mathrm{THC}$ were antagonized by the administration of $(+)$-amphetamine in doses of $2.5 \mathrm{mg} / \mathrm{kg}$ i.v.

Phencyclidine in doses of $1 \mathrm{mg} / \mathrm{kg}$ i.v. caused marked EEG changes consisting of high voltage, slow wave burst patterns, especially in the frontal cortex. At this dose, a slight increase in the cortical release of ACh was observed. Larger doses of $5 \mathrm{mg} / \mathrm{kg}$ which caused pronounced EEG changes did not significantly depress ACh release in contrast to pentobarbital $(20 \mathrm{mg} / \mathrm{kg}$ ) which dramatically reduced $\mathrm{ACh}$ release.

Both isomers of Ditran caused EEG slowing in doses of $1 \mathrm{mg} / \mathrm{kg}$ and a dramatic increase in the release of $\mathrm{ACh}$ from the cortex. They produced about a $200 \%$ increase in $\mathrm{ACh}$ release. In contrast, LSD-25 had no marked effect on ACh release. The effects were much less obvious and depended upon basal release levels. If basal release was low to moderate, LSD-25 in doses of $0.1 \mathrm{mg} / \mathrm{kg}$ slightly increased ACh release, while larger doses caused no greater increase. If baseline release of ACh was high, the drug decreased release slightly. In such pretrigeminal midpontine transected cats, LSD-25 usually caused EEG high voltage, slow waves, and a decrease in arterial blood pressure.

It is concluded that various hallucinogens differentially affect the neocortical release of ACh in pretrigeminal midpontine transected cats. $\Delta^{9}$ THC caused a definite decrease in ACh release similar to anesthetic agents like pentobarbital. A dissociative anesthetic such as phencyclidine produced negligible effects. The isomers of Ditran caused a marked increased release of ACh while LSD-25 had negligible effects. Gross EEG neocortical changes were not directly correlated with the cortical release of ACh per se.
\end{abstract}

EXTENSIVE literature exists on the effects of various psychotropic drugs on the release of acetylcholine (ACh) from the cerebral cortex. Atropine and scopolamine (MITCHELL, 1963; Szerb, 1964; PolaK, 1965; Bartolini and PePeU, 1967), $(+)$-amphetamine and $( \pm)$-DOPA

*Supported in part by grant MH-11846, USPHS.

†Italo-American exchange research fellow from the Department of Pharmacology, University of Florence. Awarded a grant under the mutual education and cultural exchange Fulbright-Hays Act and the Italian National Council of Research. 
alone and in combination with imipramine (PEPEU and BARTOLINI, 1968), angiotensin (Elie and Panisset, 1970), nicotine (ARmitage, Hall and Sellers, 1969) and pentylenetetrazol (CELESIA and JASPER, 1966) all increase ACh release from the neocortex. Central nervous depressants such as pentobarbital (MACINTOSH and OBORIN, 1953; MitChELl, 1963; Pepeu and Bartolini, 1968), ethyl alcohol (Graham and Erickson, 1971), narcotic analgesics such as morphine (Belfslin and Polak, 1965; Beleslin, Pol.ak and Sproull, 1965; Beani, Bianchi, Santinoceto and Marchetti, 1968; Sharkawi and Schulman, 1969) and ganglionic blockers such as hexamethonium (RAO, BHATT, GopalakriSHNA and HARANATH, 1970) decrease ACh release.

In view of the fact that hallucinogenic substances may have interactions with central cholinergic mechanisms, it was decided to study their effects on the spontaneous release of $\mathrm{ACh}$ from the cat neocortex in vivo. In view of the fact that the release of $\mathrm{ACh}$ varies with the level of excitation or depression of the activating system, it was decided to study FEG changes induced by the various drugs at the same time in midpontine pretrigeminal transected preparations. This manuscript describes the results obtained.

\section{METHODS}

Eighteen adult male cats weighing between $2 \cdot 1$ and $4 \cdot 3 \mathrm{~kg}$ were used. All surgery was performed under halothane-air anesthesia. Suitable cannulae were inserted in the trachea, vein and artery for adequate ventilation, i.v. injections and for recording arterial blood pressure. The animal's head was placed in a stereotaxic apparatus. The atlanto-occipital membrane was opened to allow free drainage of the cerebrospinal fluid. A stereotaxically oriented spatula was utilized for transections, which were made usually at the midpontine pretrigeminal level. Shortly following transection, the skull was opened over a large part of the frontoparietal and occipital areas. The cats were allowed to recover from the halothane anesthesia for $3 \mathrm{hr}$. During this interval they resumed spontaneous respiration. Body temperature was maintained as close to $37^{\circ} \mathrm{C}$ as possible as monitored by a rectal probe. Cats in which either brain hemorrhage or edema occurred were discarded. Blood pressure was recorded from the femoral artery by means of a Statham pressure transducer and a Grass polygraph.

The collecting cups were constructed according to Mitchell (1963). After opening the dura, a round Perspex cylinder covering $0.76 \mathrm{~cm}^{2}$ of the cortex was lowered onto the sensorimotor and its posterior association area with the aid of an adjustable electrode carrier. The cylinder was filled with $0.7 \mathrm{ml}$ of Ringer's medium containing (concentration in $\mathrm{g} / \mathrm{l}$ ); $\mathrm{NaCl}, 9.0 ; \mathrm{KCl}, 0.42 ; \mathrm{CaCl}_{2}, 0.24 ; \mathrm{NaHCO}_{3}, 0.5 ;$ glucose, 1.0 ; and physostigmine sulphate, $0 \cdot 1$. Every $10 \mathrm{~min}$ the solutions were aspirated from the collecting cups and immediately bioassayed for ACh using the dorsal muscle of the leech according to the method of Murnaghan (1958). The muscle was suspended in a $2 \mathrm{ml}$ bath. The upper end of the muscle was connected to a small mirror which reflected a beam of light onto a graduated scale approximately $5 \mathrm{ft}$ away on the wall allowing a 200 -fold magnification. The samples collected from the cups were diluted with distilled water ( 1 volume diluted to 1.4 volumes) for the purpose of achieving isotonicity with leech Ringer solution. The samples were then compared with standard solutions of $\mathrm{ACh} \mathrm{HCl}$ containing the same concentration of physostigmine. In order to assure that maximal cholinesterase inhibition had occurred in the area of the cortex beneath the cup, samples from the first three $10 \mathrm{~min}$-intervals were not assayed. Evidence that the substance released into the cups was either ACh or some very similar 
choline ester has been given previously (Mitchell, 1963; Szerb, 1963; Baktolini and PEPEU, 1967).

The electrical activity of the cortex was recorded by means of screw electrodes inserted into the skull and a silver ball electrode placed inside the collecting cup.

In all experiments the drugs were injected through a polyethylene cannula inserted into the femoral vein. Following termination of the experiment, the brain was removed and the precise level of the brainstem transection was determined macroscopically. LSD-25 and $\Delta^{9}$ THC were obtained from the Center for Studies of Narcotic and Drug Abuse, FDANIMH Psychotomimetic Agents Advisory Committee through Dr. M. C. Braude, the Executive Secretary. The isomers of Ditran were obtained from Dr. Abood of the University of Rochester and phencyclidine from Dr. McCarthy of the Parke-Davis Company.

\section{RESULTS}

Baseline levels of spontaneous ACh release

It is well known that the level of spontaneous release of $\mathrm{ACh}$ from the neocortex varies with the degree of anesthesia and level of brainstem transection. In order to assure a high level of spontaneous release, pretrigeminal brainstem transected preparations were used. Usually the mean of 3 assays before and after drug administration were obtained. In our animals the range in baseline release varied from a low of 8.0 to a high of $51.4 \mathrm{ng} / \mathrm{cm}^{2} / 10 \mathrm{~min}$ with a mean \pm S.E. for 24 animals before drug of $22 \cdot 9 \pm 2.2 \mathrm{ng} / \mathrm{cm}^{2} / 10 \mathrm{~min} 3 \mathrm{hr}$ posthalothane anesthesia and brainstem transection. The factors involved in the wide range observed in baseline release of $\mathrm{ACh}$ probably include residual anesthesia and postsurgical brain trauma.

\section{Effects of $\Delta^{9} T H C$}

$\Delta^{9} \mathrm{THC}$ in doses of $0.5-11.0 \mathrm{mg} / \mathrm{kg}$, i.v. produced high voltage slow waves in the EEG of the neocortex of pretrigeminal midpontine transected cats. These effects are illustrated in Figs. 1 and 2. EEG high voltage, slow waves were more prominent in the frontal than occipital cortical leads. The left frontal cortical lead which contained the bathing solution for collecting ACh showed EEG spikes and slow waves typical of the local effects of physostigmine. Small doses of $\Delta^{9}$ THC tended to exaggerate these effects, but in larger doses they were reduced (Fig. 2). The administration of (+)-amphetamine in doses of $2.5 \mathrm{mg} / \mathrm{kg}$, i.v. dramatically antagonized most of the effects induced by $\Delta^{9} \mathrm{THC}$.

As illustrated in Fig. 3 small doses of $\Delta^{9}$ THC in the order of $0.5 \mathrm{mg} / \mathrm{kg}$ produced variable effects on ACh release. Some animals showed a definite increase in ACh release, while others a slight decrease. However, larger doses of $\Delta^{9} \mathrm{THC}$ produced consistent and progressively greater depression of $\mathrm{ACh}$ release. These effects are antagonized by (+)amphetamine. In a total of 11 animals studied the mean change in $\mathrm{ACh}$ release for 3 samples pre- and postdrug per dose was as follows:

No. of animals

$$
\begin{array}{r}
0.5 \mathrm{mg} / \mathrm{kg} \Delta^{9} \mathrm{THC}+19 \% \\
1.0 \mathrm{mg} / \mathrm{kg} \Delta^{9} \mathrm{THC}-9 \% \\
1.5 \mathrm{mg} / \mathrm{kg} \Delta^{9} \mathrm{THC}-7 \% \\
3.5 \mathrm{mg} / \mathrm{kg} \Delta^{9} \mathrm{THC}-46 \% \\
6.0 \mathrm{mg} / \mathrm{kg} \Delta^{9} \mathrm{THC}-55 \% \\
11.0 \mathrm{mg} / \mathrm{kg} \Delta^{9} \mathrm{THC}-63 \%
\end{array}
$$




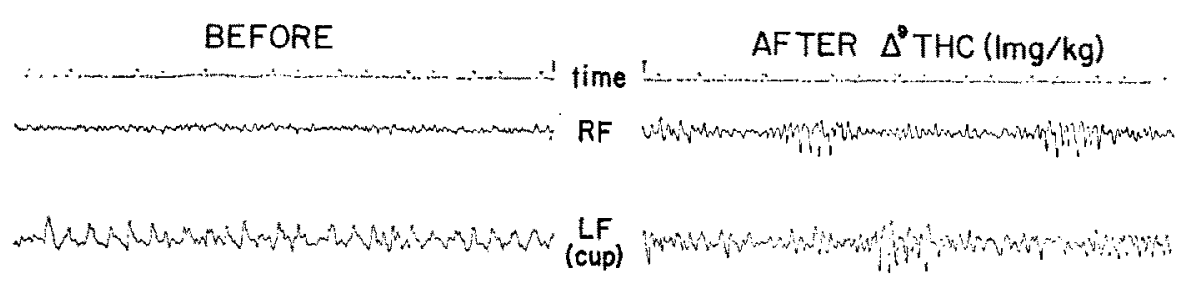

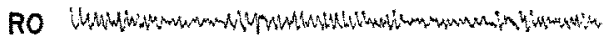

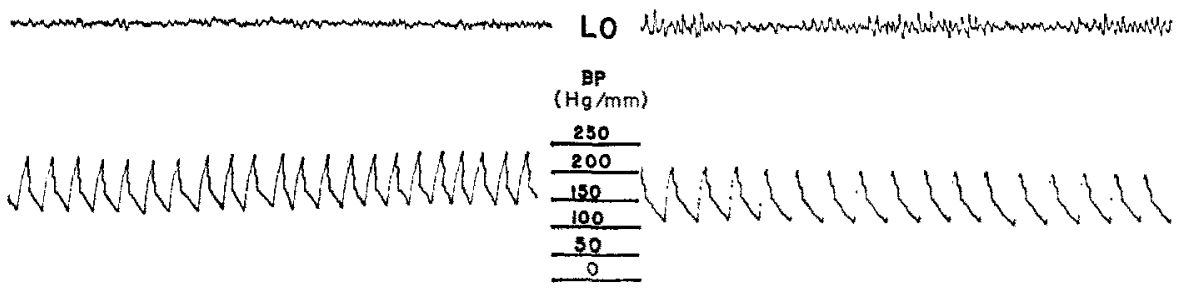

FIG. 1. EEG effects of $\Delta^{9} \mathrm{THC}$ in the pretrigeminal midpontine transected cat.

Neocortical EEG tracings are shown before and within a $\frac{1}{2} \mathrm{hr}$ after $\Delta^{2} \mathrm{THC}$. In this and all subsequent figures, cats prepared under halothane-air anesthesia and after brainstem transection were allowed to breathe room air. Before drug administration the neocortical EEG shows desynchronization in the frontal and occipital leads except in the area (LF) over which the bathing cup containing artificial CSF with physostigmine was placed. Note the high voltage spikes in this area. After $1 \mathrm{mg} / \mathrm{kg}$ of $\Delta^{9} \mathrm{THC}$, generalized neocortical high voltage slow waves are observed occurring in burst-like fashion. They are more predominant in the frontal than occipital areas of the brain. Note that mean arterial blood pressure was reduced with a slight bradycardia. Symbols in this and subsequent figures are RF: right frontal somatosensory cortex, LF: left frontal somatosensory cortex, RO: right occipital and LO: left occipital cortex. Arterial blood pressure in $\mathrm{mm} \mathbf{H g}$.

\section{Effects of phencyclidine}

The EEG effects of phencyclidine in pretrigeminal midpontine transected cats depend upon dosage. Small doses $(1 \mathrm{mg} / \mathrm{kg}$ i.v.) caused high voltage slow waves, especially prominent in the frontal areas of the brain (Fig. 4). Larger doses ( $5 \mathrm{mg} / \mathrm{kg}$ i.v.) produced spikes and suppression burst patterns throughout the neocortical EEG. In these doses phencyclidine had negligible effects on the release of ACh from the neocortex. In general, there was a tendency for a slight increase in release of ACh (Fig. 5). However, the effects were relatively slight and not statistically significant in contrast to the well known depressant effects of pentobarbital in an anesthetic dose. In a total of 4 animals studied the mean change in ACh release for 3 samples pre- and postdrug per animal for $1-6 \mathrm{mg} / \mathrm{kg}$ of phencyclidine was a negligible $+2.3 \%$.

\section{Effects of the isomers of Ditran}

The isomers of Ditran produced characteristic EEG slowing similar to that of other well known muscarinic cholinergic antagonists which penetrate the blood-brain barrier. Both the pyrrolidyl and piperidyl isomers produced an increase in spindle bursts in the neocortex following doses of $1 \mathrm{mg} / \mathrm{kg}$ i.v. A definite tachycardia also was observed (Fig. 6). Both isomers also caused a dramatic increase in neocortical ACh release well over $200 \%$ of control levels as can be seen in Fig. 7. The two isomers were equally effective in doses of 

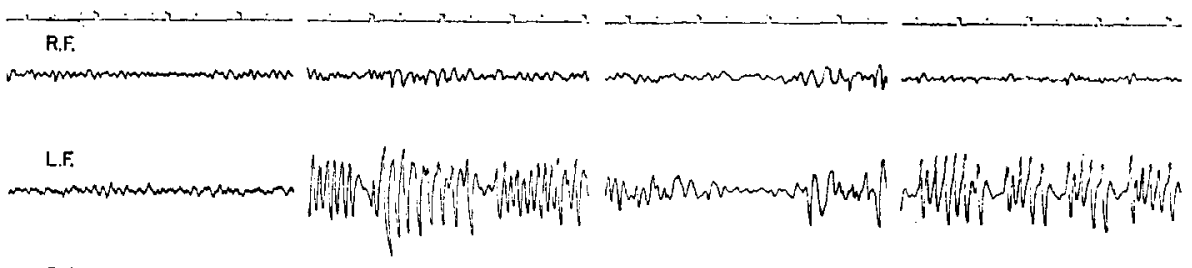

R.O.

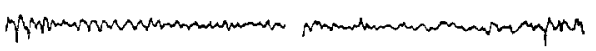

L. 0.

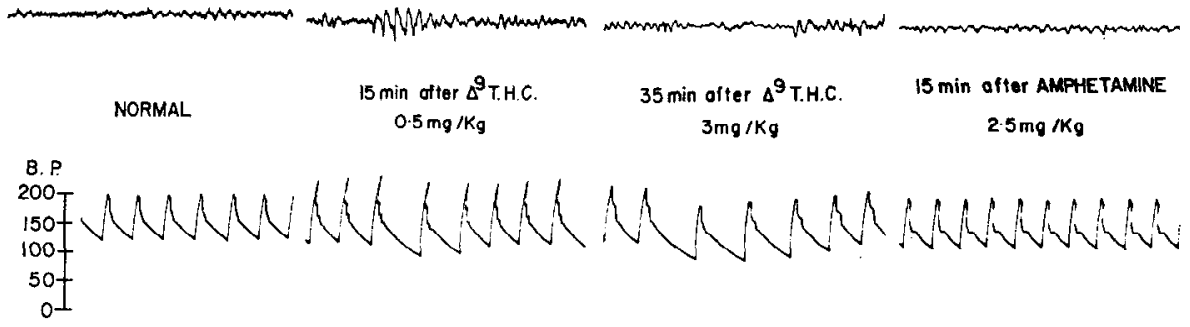

Fic. 2. Effects of $\Delta^{9}$ THC and ( + )-amphetamine on the cat EEG.

Monopolar EEG recordings are shown from the neocortex. The left frontal recording was taken from the surface of the cortex from which $\mathrm{ACh}$ was collected. Following the administration of physostigmine $1 \times 10^{-4} \mathrm{~g} / \mathrm{ml}$ into the cup, local seizure activity was observed. Note that increasing doses of $\Delta^{9} \mathrm{THC}$ progressively caused increased high voltage slow waves and reduced seizure discharge. These effects were promptly reversed by $(+)$-amphetamine.

The last tracing shows the blood pressure changes recorded from the femoral artery.

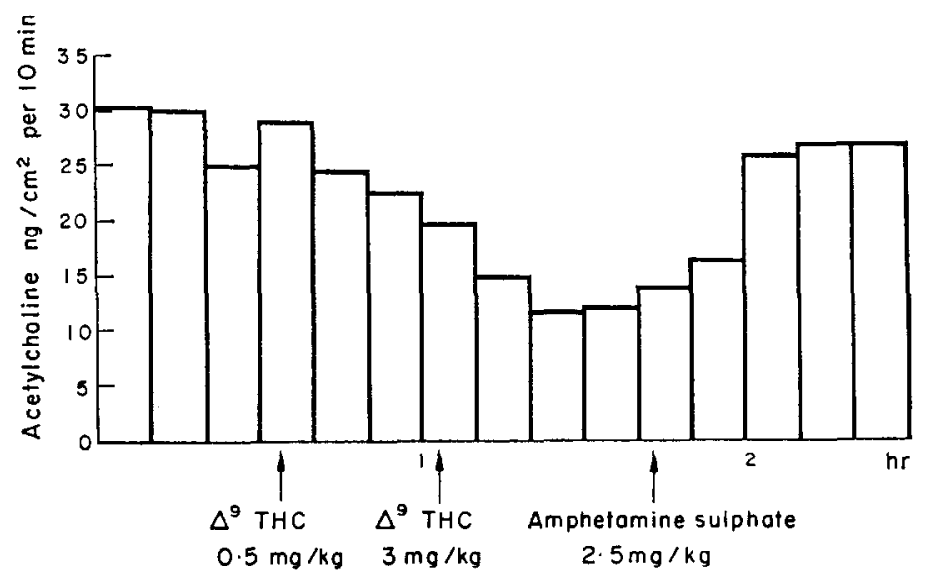

Fig. 3. Effects of $\Delta^{9} \mathrm{THC}$ and (+)-amphetamine on cortical release of acetylcholine.

The height of each bar represents the release of $\mathrm{ACh}$ in $\mathrm{ng} / \mathrm{cm}^{2} / 10 \mathrm{~min}$ as noted on the ordinate. On the abscissa blocks of $10 \mathrm{~min}$ are given for $2 \frac{1}{2} \mathrm{hr}$. Various drugs were injected at the arrows. Note that a large dose of $\Delta^{9} \mathrm{THC}(3 \mathrm{mg} / \mathrm{kg})$ reduced the release of $\mathrm{ACh}$ and that $(+)$-amphetamine sulphate $(2 \cdot 5 \mathrm{mg} / \mathrm{kg})$ antagonized this effect. 
CONTROL

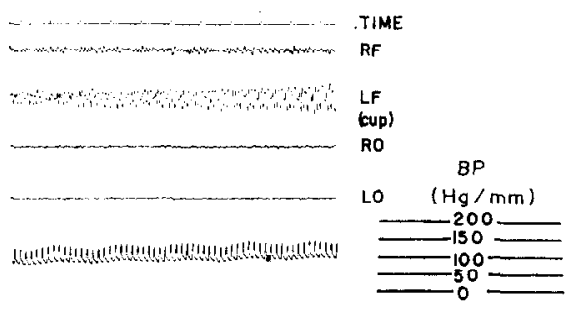

AFTER PHENCYCLIDINE $(\mathrm{Img} / \mathrm{kg})$

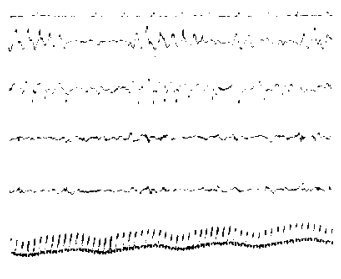

\section{AFTER PHENCYCLIDINE $(5 \mathrm{mg} / \mathrm{kg})$ AFTER PENTOBARBITAL $(20 \mathrm{mg} / \mathrm{kg})$}

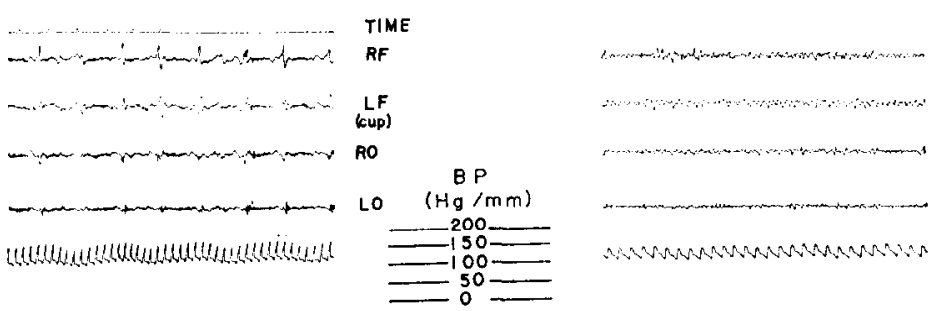

FIG. 4. EEG effects of phencyclidine in the pretrigeminal midpontine transected cats.

Note the change in the neocortical EEG after 1 and $5 \mathrm{mg} / \mathrm{kg}$ i.v. of phencyclidine. EEG recordings were taken 5 min after injection. Marked high voltage slow wave activity is seen especially in the frontal areas after $1 \mathrm{mg} / \mathrm{kg}$ and the typical slow suppression fast wave bursts after 5 $\mathrm{mg} / \mathrm{kg}$ of phencyclidine. After $20 \mathrm{mg} / \mathrm{kg}$ of pentobarbital the EEG pattern changed to more typical slow waves.

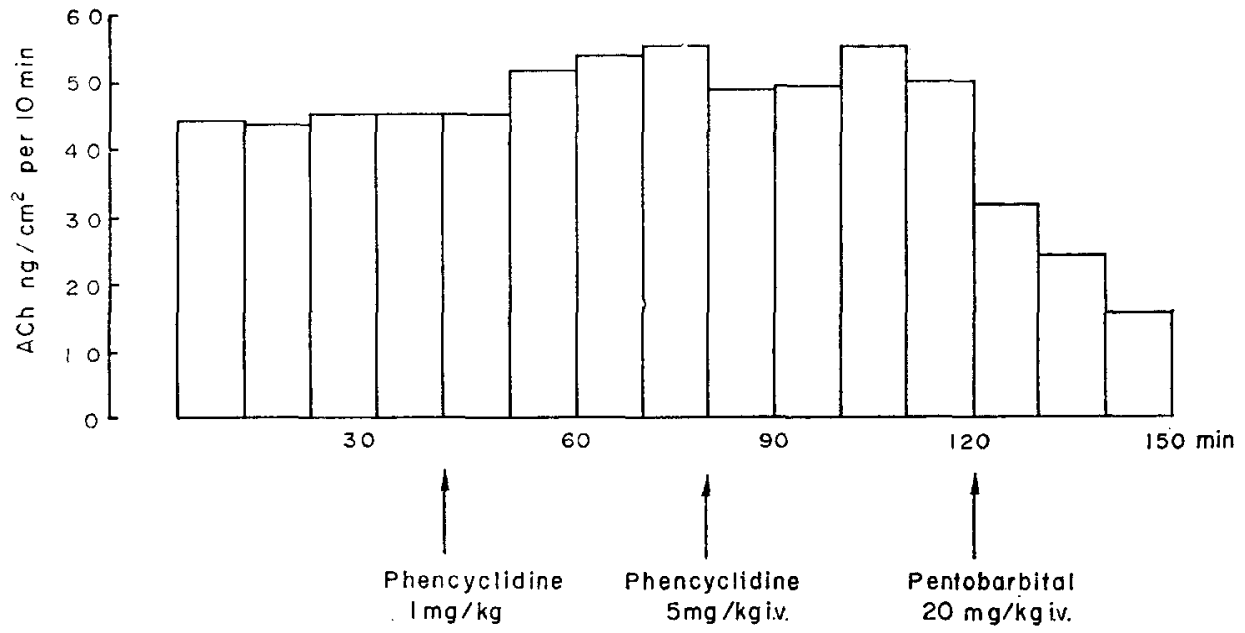

FIG. 5. Effect of phencyclidine on cortical release of acetylcholine.

After $1 \mathrm{mg} / \mathrm{kg}$ of phencyclidine there was a negligible increase in neocortical release of $\mathrm{ACh}$. Even an additional dose of $5 \mathrm{mg} / \mathrm{kg}$ of phencyclidine had insignificant effects. In contrast, pentobarbital $(20 \mathrm{mg} / \mathrm{kg}$ i.v.) caused a marked decrease in the cortical release of $\mathrm{ACh}$. 


\section{BEFORE}

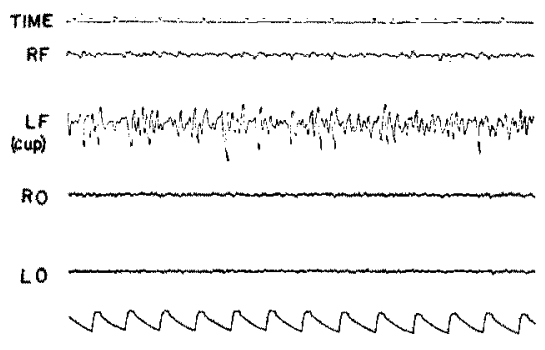

AFTER

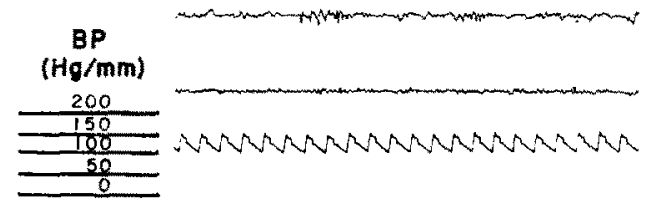

FIG. 6. EEG changes induced by the pyrrolidyl isomer of Ditran in a pretrigeminal midpontine transected cat.

Note that this drug in a dose of $1 \mathrm{mg} / \mathrm{kg}$ i.v. produced an increase in EEG slow waves in the neocortex and a decrease in physostigmine-induced spiking in LF. The drug produced a marked tachycardia.

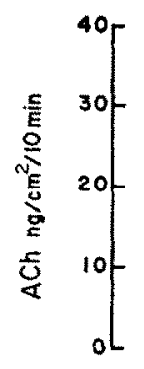

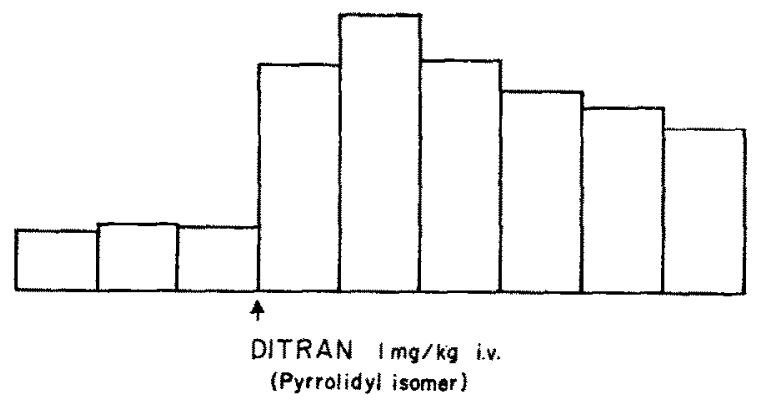

$$
\text { }
$$

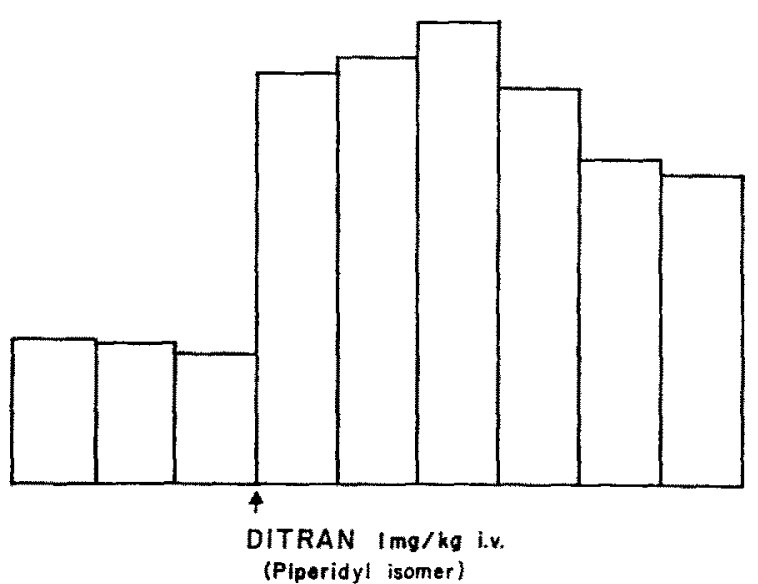

Fic. 7. Effects of the isomers of Ditran on the cortical release of acetylcholine in two different pretrigeminal midpontine transected cats.

Note that following $1 \mathrm{mg} / \mathrm{kg}$ of both isomers, there was a marked release of $\mathrm{ACh}$ for a considerable period of time. 
$1 \mathrm{mg} / \mathrm{kg}$ i.v., although complete dose-effect curves need to be determined for a precisc comparison. In a total of 4 animals studied the mean change in ACh release after $1 \mathrm{mg} / \mathrm{kg}$ of the pyrrolidyl and piperidyl derivatives for 3 samples pre- and postdrug was an enormous $+219 \cdot 3 \%$.

\section{Effects of LSD-25}

LSD-25 in doses of 0.1 and $0.2 \mathrm{mg} / \mathrm{kg}$ in pretrigeminal midpontine transected cats tended to cause a decrease in mean arterial BP and an increase in neocortical slow waves (Fig. 8). This drug did not produce any dramatic changes in neocortical relcase of ACh in most of the animals studied. The effects seemed to be dependent in part upon baseline levels of ACh release. As illustrated in Fig. 9, if baseline level of ACh release was low, LSD-25 in doses of $0.1 \mathrm{mg} / \mathrm{kg}$ produced a slight increase which lasted a relatively short time. Larger doses produced no greater increase. When baseline levels of ACh release were high, a dose of $0.1 \mathrm{mg} / \mathrm{kg}$ tended to produce a transient decrease which lasted approximately $30 \mathrm{~min}$. Larger doses $(0.2 \mathrm{mg} / \mathrm{kg})$ also tended to produce a gradual decrease in release as noted. The effects of LSD-25 on ACh release from the cat cerebral cortex were highly variable. As a result, in 5 animals studied in doses of $100-200 \mu \mathrm{g} / \mathrm{kg}$ the mean \pm S.E. ACh output in $\mathrm{ng} / \mathrm{cm}^{2} / 10$ min was $23 \cdot 3 \pm 4 \cdot 6$ before and $22 \cdot 6 \pm 3 \cdot 4$ after LSD-25, indicating no significant mean change.

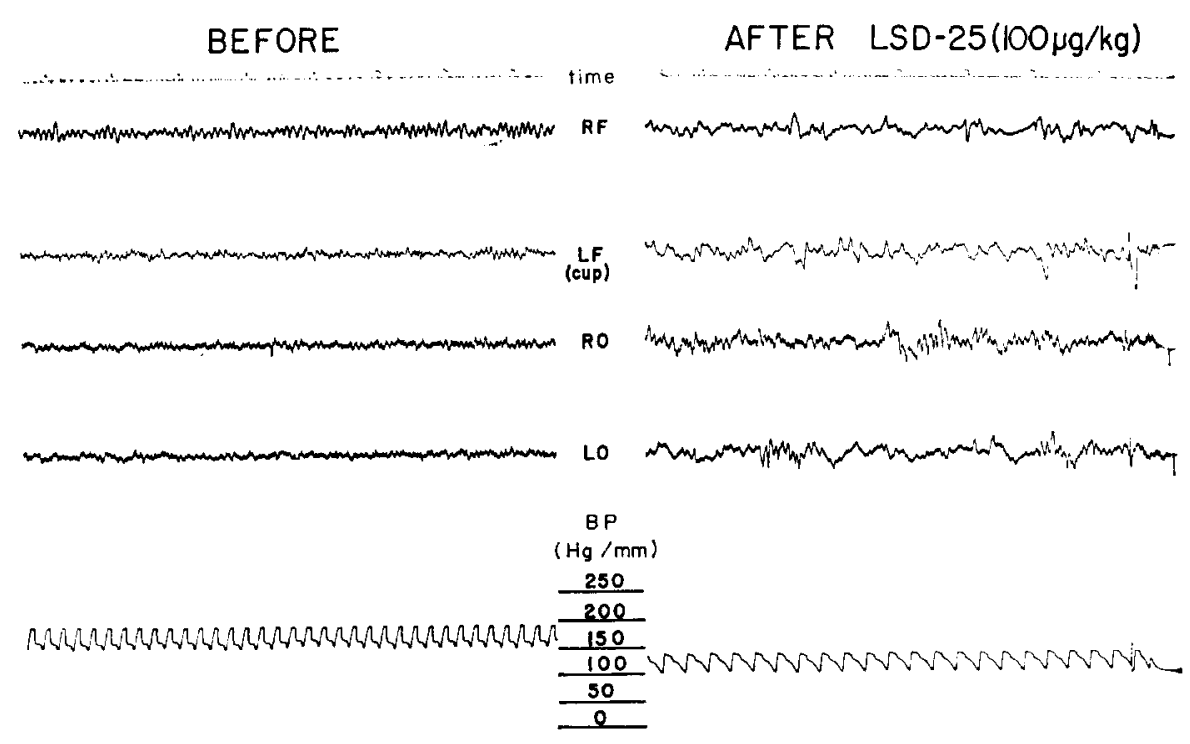

FIG. 8. EEG effects of LSD-25 in the pretrigeminal midpontine transected cat.

Note that after LSD-25 in a dose of $100 \mu \mathrm{g} / \mathrm{kg}$ the EEG did not become desynchronized as is true of intact preparations. Instead, some high voltage slow waves and spikes are seen in RF, RO and LO lcads. There was also a fall in mean arterial BP.

\section{DISCUSSION}

One of the serious methodological limitations of research on the release of $\mathrm{ACh}$ from the neocortex into a collecting cup is the necessity of using a cholinesterase inhibitor to prevent ACh breakdown. The relatively high concentration of physostigmine used in this study $\left(1.4 \times 10^{-4} \mathrm{M}\right)$ caused local seizure activity as observed in the EEG. Thus the concentration 


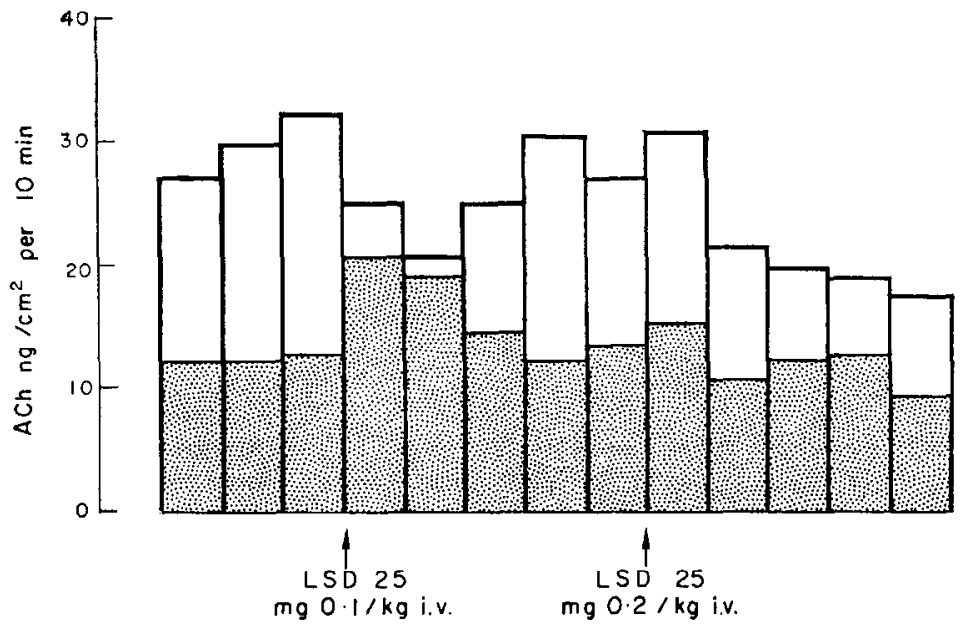

FIG. 9. Effect of LSD-25 on acetylcholine release in two different cat preparations with different basal output levels.

The stippled bars represent ACh release from one cat and the open bars the other. Note that in the cat with high basal levels of ACh release, LSD-25 in a dose of $0.1 \mathrm{mg} / \mathrm{kg}$ caused a decrease in release which was relatively transient. This effect was enhanced by an additional dose of $0.2 \mathrm{mg} / \mathrm{kg}$ i.v. In contrast, in a cat with low basal output levels of ACh, the smaller doses of LSD-25 caused a transient increase in ACh release which was not reproduced by the larger dose. The important point is that the overall effects of LSD-25 are relatively slight.

of cholinesterase inhibitor used was large enough to cause its own pharmacological effects. The leech muscle assay was controlled with standard solutions of acetylcholine containing the same concentration of physostigmine. However, it should be pointed out that the effect of any drug given systemically may be due to an interaction of the drug with physostigmine as well, or even instead of, a direct effect on the cholinergic mechanisms of the cat neocortex. It is, of course, necessary that future studies be undertaken using other cholinesterase inhibitors and especially varying their concentration such that prevention of $\mathrm{ACh}$ hydrolysis does not occur at the expense of local cortical seizures.

The role of central cholinergic mechanisms in the action of various hallucinogenic substances is quite variable (Giarman and FreEdMan, 1965; Domino, 1971; Domino and WILSON, 1972). In some cases, their interaction with central cholinergic mechanisms seems primary, while in others it appears to be a secondary or epiphenomenon. In general, most psychotropic drugs which produce EEG activation tend to increase neocortical ACh release, while those that produce EEG high voltage slow waves tend to decrease ACh release. However, there are some dramatic exceptions. Centrally acting muscarinic cholinergic antagonists such as atropine and scopolamine are the best known exceptions in that they both cause EEG slow waves and a very large increase in $\mathrm{ACh}$ release.

The effects of $\Delta^{9}$ THC on both the neocortical EEG as well as the relcase of ACh reminds one of the actions of a central nervous system depressant with soporific-anesthetic properties. Increasing doses of this compound produced progressively greater EEG slow waves and a decrease in ACh release. It should be noted that in some preparations, small doses of this drug $(0.5 \mathrm{mg} / \mathrm{kg}$ i.v. $)$ produced a slight increase in neocortical release of $\mathrm{ACh}$. This effect was not consistently seen, however. The finding that $\Delta^{9} \mathrm{THC}$ produces a decrease in release of cortical ACh is consistent with the findings of Domino (1972) and Domino and WILSON (1972) 
that this drug elevates total brain ACh content similar to other sedative-soporific and narcotic drugs. It is of special interest that LAYMAN and MILTON (1971) have shown that both $\Delta^{9}$ THC and cannabidiol decrease the spontaneous release of $\mathrm{ACh}$ from guinea pig ileum and that these drugs act primarily at muscarinic cholinergic sites.

In contrast, phencyclidine in doses up to $6 \mathrm{mg} / \mathrm{kg}$ i.v. produced no significant effects on the cortical release of ACh in spite of marked neocortical EEG changes. This dissociative anesthetic in non-anesthetizing doses in the rat may increase the utilization of ACh (DOMINO and WILSON, 1972). Nevertheless, in the cat this compound, in minimal anesthetizing doses, had no significant effect in contrast to central nervous system depressants such as pentobarbital and $\Delta^{9}$ THC. It would appear that the mechanism of action of phencyclidine is completely different from other classes of central nervous system depressants.

Both the pyrrolidyl and piperidyl isomers of Ditran were equally effective in causing EEG slow waves and a dramatic increase in the release of ACh from the cortex. These effects of Ditran are consistent with the known action of muscarinic cholinergic antagonists that can penetrate the blood-brain barrier. It is well known that atropine and scopolamine (Mitchell, 1963; Szerb, 1964; PolaK, 1965; Bar tolini and PePeU, 1967) all cause a similar phenomenon. The present findings are consistent with the hypothesis that the central actions of Ditran involve antagonism of $\mathrm{ACh}$. Of course other mechanisms have been implicated in the pharmacology of these substances (ABOOD, 1968).

In contrast to the dramatic effects of the isomers of Ditran, LSD-25, in doses which alter the EEG, did not significantly affect neocortical release of $\mathrm{ACh}$. It has been shown (Domino and WII SON, 1972) that large doses of LSD-25 may increase the brain utilization of ACh in rats. In the present experiment in cats, we did obtain marginal evidence that small doses of LSD-25 may cause a slight increase in the cortical release of $\mathrm{ACh}$ while larger doses tended to decrease its release. Especially clear is the fact that these changes are very slight and thercfore, do not in all probability relate to the primary mechanism of action of this drug. It is important to note that these experiments were conducted in acute cats with pretrigeminal midpontine transections in order to avoid the complicating features of general anesthesia. BRADLEY (1958) has emphasized the differential effects of ( + -amphetamine and LSD-25 in the brainstem. His data suggest that $(+)$-amphetamine acts directly on the reticular formation of the brain while LSD-25 acts on the sensory input from the environment. He has pointed out that LSD-25 does not have any significant effect on the spontaneous activity of encéphale isolé preparations where many afferents from the pcriphery arc lacking. The well known EEG flattening and desynchronizing action of LSD-25 in the cat was not observed in our midpontine pretrigeminal transected cats. In contrast, LSD-25 usually produced a slight increase in amplitude and slowing of the EEG. However, KING KILLAM (1962) has been less impressed with the critical role of the brainstem in the action of this drug. In any event, it would seem that studies on cortical ACh release in unanesthetized animals with an intact brainstem are indicated. Our data would indicate that in brainstem transected cats LSD-25 has negligible effects in releasing neocortical ACh in contrast to the dramatic actions reported for $(+$ )-amphetamine and DOPA (PEPEU and BARTOLINI, 1968).

\section{REFERENCES}

AвоOD, L. G. (1968). The psychotomimetic glycolate esters and related drugs. In: Psychopharmacology: A Review of Progress 1957-1967 (Efron, D. H., Cole, J. O., Levine, J. and Whittenborn, J. R., Eds.), pp. 683 692, Public Health Service Publication 1836. U.S. Government Printing Office, Washington D.C. 
Armitage, A. K., Hall, G. H. and Sellers, C. M. (1969). Effects of nicotine on electrocortical activity and acetylcholine release from the cat cerebral cortex. Br.J. Pharmac. Chemother. 35: 152-160.

Bartolini, A. and PePeu, G. (1967). Investigations into the acetylcholine output from the cerebral cortex of the cat in the presence of hyoscine. Br.J. Pharmac. Chemother. 31: 66-73.

Beani, L., Bianchi, C., Santinoceto, L. and Marchetti, P. (1968). The cerebral acetylcholine release in conscious rabbits with semi-permanently implanted epidural cups. Int. J. Neuropharmac. 7: 469-481.

Belestin, D. and Polak, R. L. (1965). Depression by morphine and chloralose of acetylcholine release from the cat's brain. J. Physiol., Lond. 177: 411-419.

Beleslin, D., Polak, R. L. and Sproull, D. H. (1965). The release of acetylcholine into the cerebral subarachnoid space of anaesthetized cats. J. Physiol., Lond. 177: 420-428.

Bradley, P. B. (1958). The central action of certain drugs in relation to the reticular formation of the brain. In: Reticular Formation of the Brain (Jasper, H. H., Proctor, L. D., Knighton, R. S., Noshay, W. C. and Costello, R. T., Eds.), pp. 123-149, Little Brown, Boston.

Celesia, G. G. and JASPER, H. H. (1966). Acetylcholine released from cerebral cortex in relation to state of activation. Neurology, Minneap. 16: 1053-1063.

Domino, E. F. (1971). Neuropsychopharmacological studies of marijuana-some synthetic and natural THC derivatives in animals and man. Ann. N.Y. Acad. Sci. 191: 166-191.

Domino, E. F. (1972). Pharmacology of madness-The hallucinogens. In: Drug Abuse, Proc. Int. Conf. (Zarafonetis, C. J. D., Ed.), pp. 307-320, Lea \& Febiger, Philadelphia.

Domino, E. F. and Wilson, A. (1972). Psychotropic drug influences on acetylcholine utilization. Psychopharmacologia (in press).

Elie, R. and PANisset, J. C. (1970). Fffect of angiotensin and atropine on the spontaneous release of acetylcholine from cat cerebral cortex. Brain Res. 17: 297-305.

Giarman, N. J. and FreEDMAN, D. X. (1965). Biochemical aspects of the actions of psychotomimetic drugs. Pharmac. Rev. 17: 1-25.

Graham, D. T. and Erickson, C. K. (1971). The effect of ethanol on the output of cerebral acetylcholine in vivo. Fedn Proc. Fedn Am. Socs. exp. Biol. 30: 622.

King Killam, E. (1962). Drug action on the brain-stem reticular formation. Pharmac. Rev. 14: 175-223.

LAYMan, J. M. and Mirton, A. S. (1971). Some actions of $\Delta^{1}$-tetrahydrocannabinol and cannabidol at cholinergic junctions. Br. J. Pharmac. Chemother. 41: 379P-380P.

MACINTOSH, F. C. and OBORIN, P. E. (1953). Release of acetylcholine from intact cerebral cortex. In: XIXth Int. Physiol. Cong. Abst. of Communications, 580-581.

Mitchell, J. F. (1963). The spontaneous and evoked release of acetylcholine from the cercbral cortex. $J$. Physiol., Lond. 165: 98-116.

Murnaghan, M. F. (1958). The morphinized-eserinized leech muscle for the assay of acetylcholine. Nature, Lond. 182: 317.

Pepeu, G. and Bartolin, A. (1968). Effect of psychoactive drugs on the output of acetylcholine from the cerebral cortex of the cat. Eur. J. Pharmac. 4: 254-263.

POLAK, R. L. (1965). Effect of hyoscine on the output of acetylcholine into perfused cerebral ventricles of cats. J. Physiol., Lond. 181 : 317-323.

Rao, K. S., Bhatt, R. H. V., Gopalakrishna, G. and Haranath, P. S. R. K. (1970). Influence of intracarotid infusions of hexamethonium on acetylcholine release from perfused cerebral ventricles in anesthetized dogs. Indian J. med. Res. 58: 1279-1284.

Sharkawi, M. and Schulman, M. P. (1969). Inhibition by morphine of the release of $\left({ }^{14} \mathrm{C}\right)$ acetylcholine from rat brain cortex slices. J. Pharm. Pharmac. 21: 546-547.

SzERB, J. C. (1963). Nature of acetylcholine-like activity released from brain in vivo. Nature, Lond. 197: $1016-1017$.

SzERB, J. C. (1964). The effect of tertiary and quaternary atropine on cortical acetylcholine output and on the electroencephalogram in cats. Can.J. Physiol. Pharmac. 42: 303-314. 